\title{
Tomotherapy concomitant with cetuximab, followed by cetuximab as single-agent therapy for unresectable squamous cell carcinoma of the skin: a case report
}

Sara Falivene ${ }^{1 *}$, Francesca Maria Giugliano ${ }^{2}$, Antonio Maria Grimaldi ${ }^{3}$, Rossella Di Franco ${ }^{1}$, Diego Toledo ${ }^{4}$, Matteo Muto ${ }^{4}$ Fabrizio Cammarota ${ }^{2}$, Valentina Borzillo ${ }^{2}$, Paolo Antonio Ascierto ${ }^{3}$ and Paolo Muto ${ }^{2}$

\begin{abstract}
Background: Cutaneous squamous cell carcinoma (SCC) is the second most frequency of all skin tumors. Incidence of SCC has risen significantly due to an increased sun exposure and the number of immunodeficient patients. Cutaneous SCC is characterized by high Epidermal growth factor receptor (EGFR) expression with low frequency of RAS mutations. Generally, locoregional surgery is curative and systemic therapy is not indicated. We evaluated the activity and toxicity profile of tomotherapy concomitant with Cetuximab, followed by Cetuximab as single agent therapy in a patient affected by unresectable, locally advanced cutaneous SCC.

Case presentation: At our institution, on March 2012 we treated a 45 years-old patient affected by locally advanced, unresectable G1 SCC of the lumbar region. At our first observation, the patient was asthenic, with severe pain and functional limitations. There was also a superinfection due to Pseudomonas Aeruginosa resistant to antibiotics, and a G3 anemia secondary to the bleeding lesion. ECOG Performance Status was 2. Tomotherapy has been performed concomitant with the Cetuximab $(400 \mathrm{mg} / \mathrm{m} 2$, followed by weekly doses of $250 \mathrm{mg} / \mathrm{m} 2)$ at the total dose of $60 \mathrm{~Gy}(2 \mathrm{~Gy} / \mathrm{fx})$, followed by Cetuximab monotherapy.

The lesion reduced progressively until disappear even after the suspension of the treatment and the patient achieved complete response. Toxicity resulted in G1 cutaneous rash and G2 toxicity to the nails, appeared after 5 months of treatment, typical toxicity profile of the anti-EGFR therapies. After one month of therapy the Pseudomonas Aeruginosa superinfection totally disappeared. Quality of life resulted significantly improved with reduction until discontinuation of the anti-pain drugs, and progressive increase of the hemoglobin levels. At follow up of 15 months there was no evidence of active disease and the ECOG Performance Status was 0 (zero).
\end{abstract}

Conclusion: The treatment was effective and feasible. Considering these excellent results, further studies about concomitant tomotherapy with Cetuximab for advanced/inoperable SCC of the skin are needed.

Keywords: SCC, Cetuximab, Tomotherapy, Target therapy, Quality of life

\footnotetext{
* Correspondence: sara.falivene@gmail.com

'Dipartimento di diagnostica per immagini e Radioterapia - Seconda

Università degli studi di Napoli, Piazza Miraglia, 80131 Naples, Italy

Full list of author information is available at the end of the article
} 


\section{Background}

Cutaneous basal cell (BCC) and squamous cell carcinoma (SCC), are the most common cancer in United States [1]. $\mathrm{SCC}$ is the second most frequent skin tumor [2]. More than 3.000.000 new cases of SCC are diagnosed worldwide every year [3]. Incidence of SCC has risen significantly due to increased sun exposure and number of immunodeficient patients $[1,4,5]$. If not radically excised, SCC become invasive with tissue destruction and involvement of lymph nodes, soft tissues, cartilages, and bones. Metastatic diffusion is a rare phenomenon [1]. Generally, locoregional surgery is curative and systemic therapy is not necessary [1]. Mohs micrographic surgery is an option to be taken in account. Radiation therapy (RT) is a therapeutic option in advanced, unresectable SCC [1,6-8]. For advanced disease chemotherapy has often palliative indication [9]. Currently, the great evolution of technology has allowed RT to increase the compliance of the treatment administration and, at the same time, the reduction of the dose to the surrounding normal tissue allowing an increase of the dose to the tumor. Helical Tomotherapy (HT) delivery represents a very important step in radiotherapic technical innovation allowing improvement of dose conformation, uniformity and normal tissues sparing. Cutaneous SCC is characterized by high Epidermal growth factor receptor (EGFR) expression with low frequency of RAS mutations. These acquisitions support the potential efficacy of EGFRtarget therapies. Several published data demonstrate that Cetuximab is an emerging alternative treatment for unresectable cutaneous SCC [6,10-14].

The treatment of the tumor and the maximal preservation of function are important aim in the management of cutaneous SCC. Development of Skin Cancer Index (SCI) showed that healing, cosmetic and self-image, emotional states such as anxiety and frustration were concerns greater than physical handicaps $[4,15]$.

We evaluated the activity and toxicity profile of a new RT technology, HT, concomitant with Cetuximab, followed by Cetuximab as single agent therapy in a patient affected by unresectable, locally advanced SCC of the skin. There are limited published data available for concomitant treatment of Cetuximab and HT in advanced cutaneous SCC.

\section{Case presentation}

On March 2012 we visited a 45-year-old Caucasian woman with a very extensive, untreated G1 cutaneous SCC infiltrating widely the lumbar region until bone. A physical examination showed a locally advanced lesions with necrotic and ulcerated areas involving the entire lumbar area until sacrum and buttocks. There was also a superinfection due to Pseudomonas Aeruginosa resistant to antibiotics. The patient referred functional limitation in movement, difficulty in walking, pain, and consequent serious relationship problems with a worse status of quality of life. The patient had G3 anemia due to the bleeding lesion, and performed red blood cells transfusion before to start the treatment. ECOG Performance Status was 2. A contrast-enhanced magnetic resonance (RM) of pelvis showed extensive skin thickening from the front region of the iliac spine up to posterior sacral region, involving the contralateral lumbar region. The lesion extended from the right of right iliac crest (where it is in contact with the lateral abdominal muscles and with the cortex of the iliac crest) until ipsilateral gluteal region, involving deep muscular tissue.

The patient's case was discussed by a multidisciplinary committee involving surgeons, radiotherapists and oncologists. The patient was treated with Cetuximab at the loading dose of $400 \mathrm{mg} / \mathrm{m} 2$, followed by weekly doses of $250 \mathrm{mg} / \mathrm{m} 2$,from 28 March 2012 to 13 March 2013. HT has been performed concomitant with the Cetuximab from 28 march 2012 to 19 May 2012, at the total dose of 60 Gy $(2 \mathrm{~Gy} / \mathrm{fx})$.

Patient was immobilized in the prone position without application of bolus. Planning computed tomography (CT) images were acquired through the region of interest using a $3 \mathrm{~mm}$ slice thickness and transferred to the contouring workstation for TomoTherapy Hi - Art System ${ }^{\bullet}$. Set up was based on fiducial markers and tattoo aligned with a room laser system before treatment.

The gross target volume (GTV) was considered as right gluteal region outlined based on the depth of involvement and the extent of disease. Clinical target volume (CTV) was created adding a margin of $3 \mathrm{~mm}$ at GTV. Doses to organs at risk (rectum, bladder, right and left femur, right and left kidney, pubis, bowel) were defined in accordance with dose constraints. Each therapy session was preceded by a MVCT in order to ensure the correct repositioning of the patient and to adjust the distribution of the irradiation dose according with the evolution of the tumor during therapy. The accepted tolerance at our institution was $5 \mathrm{~mm}$. After a new CT scan for contouring, a new treatment plan was elaborated at 30 Gy according with volumetric reduction of lesion. The time of delivery (around 10 minutes for fractions) were well tolerated by the patients. At the end of the combined radio target therapy, Cetuximab treatment continued for the following 10 months.

The patient achieved complete response, confirmed at imaging evaluation, and the lesion reduced until disappear even after the suspension of the treatment (Figures 1 and 2). Toxicity resulted in G1 cutaneous rash and $\mathrm{G} 2$ toxicity to the nails according to typical toxicity profile of the anti-EGFR therapies, appeared 5 months after treatment. One month after therapy the Pseudomonas Aeruginosa superinfection totally disappeared as the G3 anemia. 


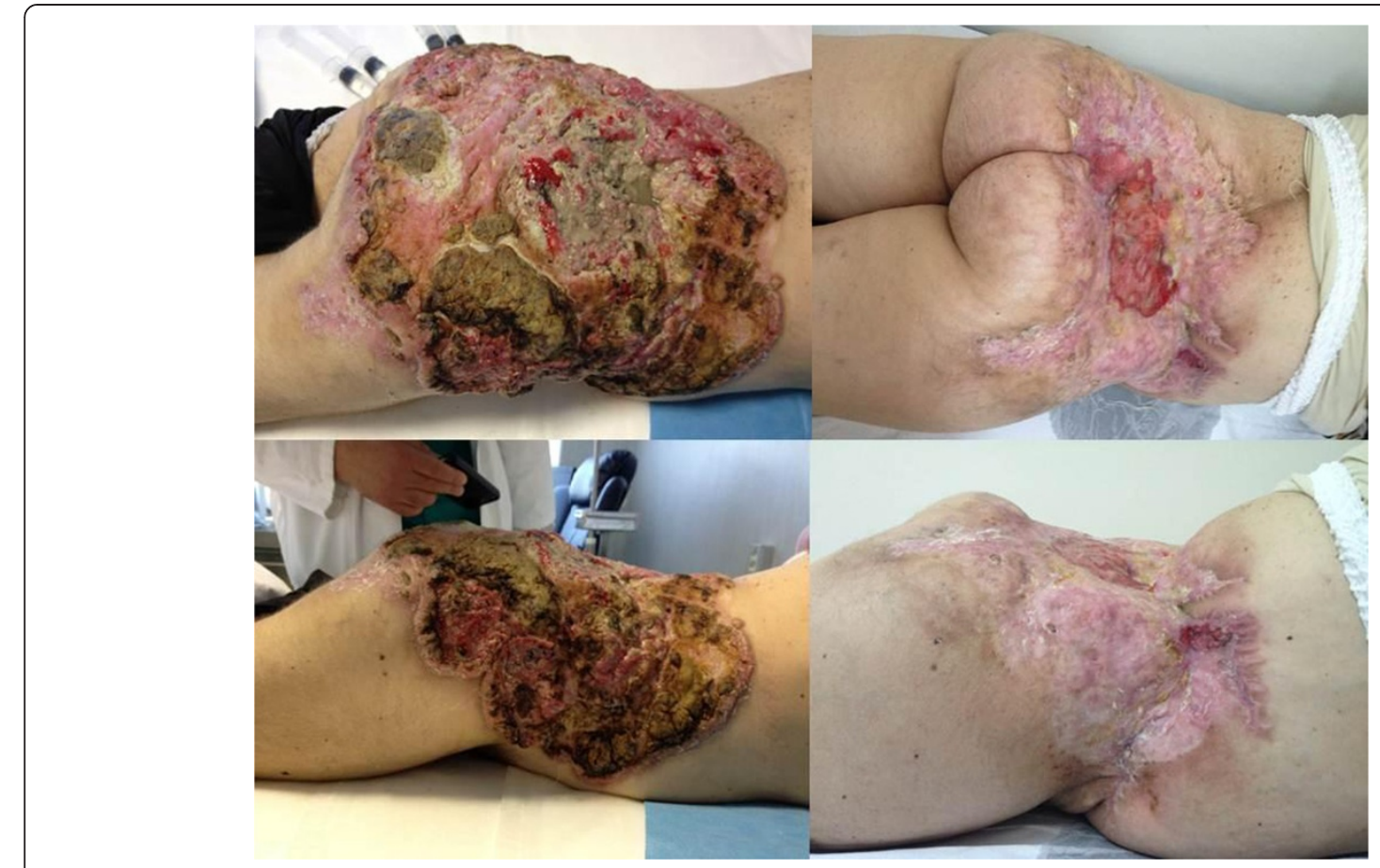

Figure 1 On left the lesion at baseline (March 2012) and on right the lesion at follow up (October 2013).

Quality of life resulted significantly, dramatically improved with progressive reduction until discontinuation of anti-pain drugs. At follow up of 15 months there was no evidence of active disease, moreover she was able to get back a normal social life. Actually the ECOG Performance Status is 0 (zero).

\section{Discussion}

Surgery is the standard treatment of localized cutaneous SCC [1]. Although Mohs surgery remains the standard treatment for locally advanced SCC there is no safe and effective non-surgical treatment for unresectable SCC

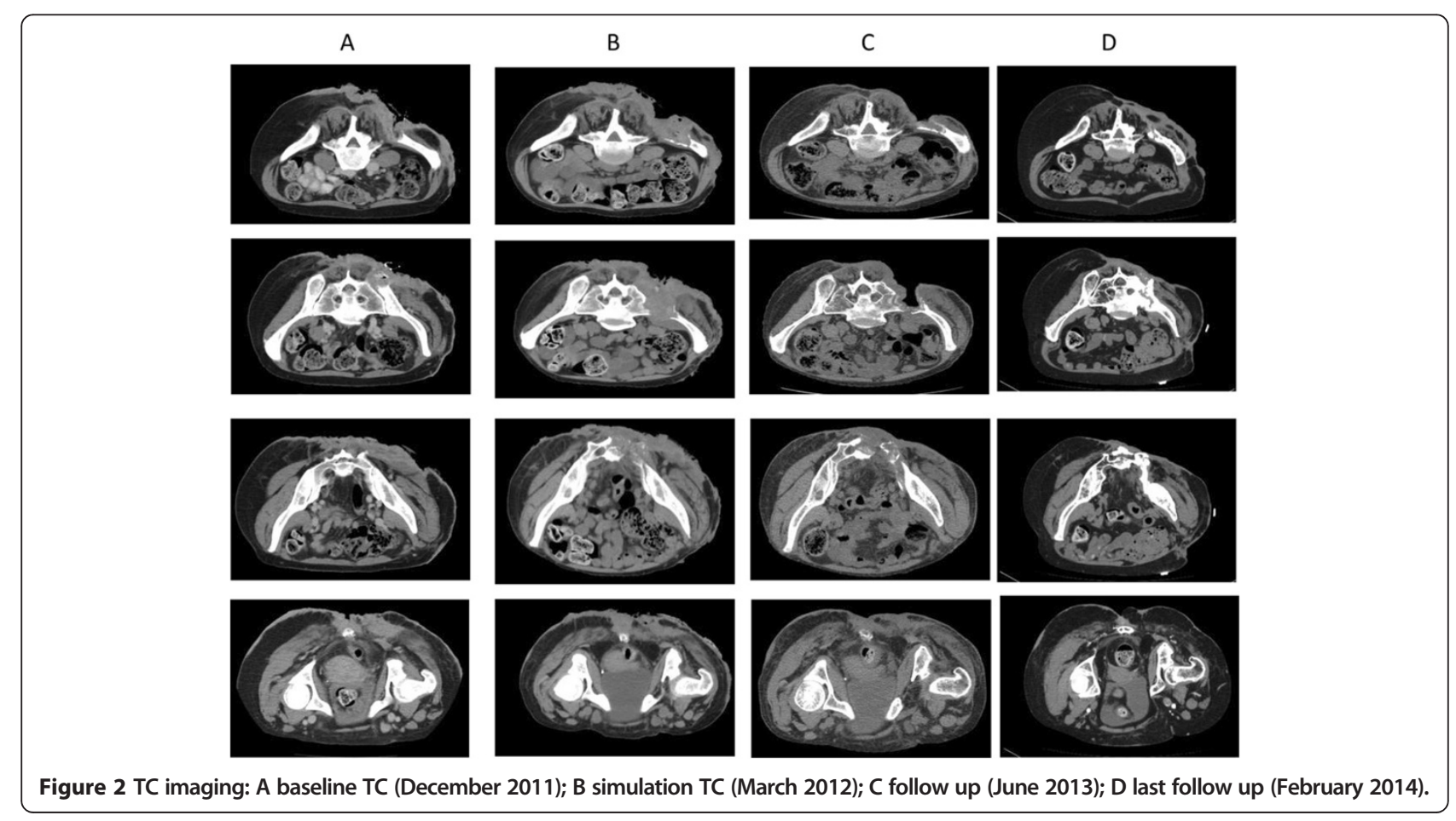


need [6]. Traditional techniques are supported by old studies and there are few data from prospective trials. According with NCCN guidelines, radiotherapy in the management of skin cancers have indication 2A [1]. Two meta-analyses reported $10 \%$ of 5 -year recurrence rates after RT for the treatment of SCC $[16,17]$. RT is considered the primary treatment of choice when surgical excision may result infunctional or with aesthetic compromission or for extensive unresectable tumors [1,18-20]. RT achieves excellent cosmetic results. It can be delivered using orthovoltage radiation (for superficial lesions), megavoltage electron beam technology (for deeper tissue) or brachytherapy (delivering radiation directly at the lesion) [18]. IMRT is a special technique that warranted to ensure adequate surface dose to the target area sparing normal tissue [1]. HT is an innovative treatment unit dedicated to IMRT and IGRT that consent a combination between an helical CT scanner and a conventional linear accelerator (LINAC). The RT is delivered in helical modality. In fact the $6 \mathrm{MV}$ LINAC is assembled in a circular gantry similar to a CT scanner and rotates in synchrony with couch movement creating a helical trajectory. HT consent to acquire MVCT scans before to deliver RT [21]. Due to this delivery system of "record and verify", HT allows to generate very complex dose distributions with high doses to the entire tumor volume, sparing normal healthy tissue at the same time. For advanced disease chemotherapy has often only a palliative indication. Sadek et al. [9] demonstrated that neoadjuvant chemotherapy with cisplatin, 5-fluorouracil and bleomycin followed by surgery can be curative (30\% of complete remission and 54\% of partial remission). The advent of systemic therapy targeted against the signaling pathway provided a new important option for patients with advanced disease unfit for local therapy [1]. EGFR plays a crucial role in signal-transduction pathways that regulate key cellular functions. Cetuximab is a recombinant monoclonal antibody that competitively inhibits EGFR. Cetuximab specifically binds to the extracellular domain of EGFR inducing an internalization of the ligand-receptor complex and subsequent downregulation of intracellular signals [22,23]. Maubec et al. evaluated in a phase II trial the effects of Cetuximab as first line single agent in chemotherapy-naive unresectable SCC. In this phse II trial cetuximab achieved 69\% DCR and 28\% RR [13]. Recently, Preneau et al. [14] confirm the potential interest of cetuximab to treat unresectable advanced SCC alone or combined with carboplatin based chemotherapy or with radiotherapy.

Preclinical data on human tumor xenografts in nude mice indicated that Cetuximab in combination with radiotherapy improves local tumor control [24-26]. The radiosensitizing effect of cetuximab is probably due to regulation of cell cycle progression [27], blockage of radiation-induced EGFR transport into the nucleus, and interference with DNA repair mechanisms [28,29]. Moreover in head and neck squamous carcinomas, the combination of radiotherapy plus cetuximab is widely used in unresectable tumors.

Several studies evaluated the quality of life (QOL) perceived by the patient before and after surgical treatment [4]. Various indicators such as Skin Cancer Index (SCI) evaluating domains of emotion, social factors, and appearance [30] and the Dermatology Life Quality Index (DLQI) [31] or Skindex, reporting subscores on symptoms, emotional effects, and effects on functioning have been used [32]. In our case the combined radio-target treatment allowed the patient to achieve a significant improvement in QoL for the disappearance of the symptoms, but also and especially for the opportunity to have a social life again.

\section{Conclusion}

Only patients with locally advanced uresectable cutaneous SCC should be considered for radiation therapy with or without target therapy. Advanced radiation therapy techniques offer greater dose escalation to tumor volumes while decreasing patient long term toxicity. HT is an effective option as radical treatment or in association with chemotherapy. Early and late toxicity and cosmetic results are acceptable. The patient will continue to be assessed in order to observe any recurrences. Considering these excellent results, further studies about concomitant Tomotherapy with Cetuximab for advanced/ inoperable SCC of the skin are needed.

\section{Consent}

Written informed consent was obtained from the patient for publication of this Case report and any accompanying images. A copy of the written consent is available for review by the Editor of this journal.

\section{Abbreviation \\ SCC: Cutaneous squamous cell carcinoma; BCC: Cutaneous basal cell; RT: Radiation therapy; HT: Helical tomotherapy; SCl: Skin cancer index; EGFR: Epidermal growth factor receptor; RM: Magnetic resonance; IMRT: Intensity-modulated radiotherapy; IGRT: Image guided radiotherapy; CT: Computed tomography; GTV: Gross target volume; CTV: Clinical target volume; LINAC: Linear accelerator.}

\section{Competing interests}

The authors declare that they have no competing interests.

\section{Authors' contributions}

SF, FMG, AMG, RDF conception and design, analysis and interpretation of data. FMG, AMG, DT, MM, FC acquisition of data, critical revision of important intellectual content. SF, FMG, VB drafting the manuscript and elaboration of figure. PA, PM critical revision of important intellectual content. All authors have given final approval of the version to be published.

Acknowledgements

We thank V. Manera who provided data collection 


\section{Author details}

'Dipartimento di diagnostica per immagini e Radioterapia - Seconda Università degli studi di Napoli, Piazza Miraglia, 80131 Naples, Italy. ${ }^{2}$ UOC Radioterapia -- Istituto Nazionale per lo studio e la cura dei tumori "Fondazione Giovanni Pascale" - IRCCS, Via Mariano Semmola 80131 Naples, Italy. ${ }^{3}$ SC Oncologia Medica Melanoma Immunoterapia Oncologica e Terapie Innovative - Istituto Nazionale per lo studio e la cura dei tumori "Fondazione Giovanni Pascale" - IRCCS, Via Mariano Semmola 80131 Naples, Italy. ${ }^{4}$ EuropeanMedicallmaging - Fondazione Muto-onlus, Napoli, Italia, Via Taverna Rossa, 169, 80020 Casavatore, Naples, Italy.

Received: 30 May 2014 Accepted: 24 September 2014

Published: 30 September 2014

\section{References}

1. National Comprehensive Cancer Network Clinical Practice Guidelines in Oncology: Basal cell and squamous cell skin cancers. V.2.; 2013.

2. Rogers HW, Weinstock MA, Harris AR, Hinckley MR, Feldman SR, Fleischer $A B$, Coldiron BM: Incidence estimate of nonmelanoma skin cancer in the United States, 2006. Arch Dermatol 2010, 146(3):283-287.

3. Salasche SJ: Epidemiology of actinic keratoses and squamous cell carcinoma. J Am Acad Dermatol 2000, 42(1 Pt 2):4-7.

4. Randie H, Armstrong K, Armstrong AW: Non melanoma SkinCancer. Dermatol Clin 2012, 30:125-139.

5. Schmitt J, Seidler A, Diepgen TL, Bauer A: Occupational ultraviolet light exposure increases the risk for the development of cutaneous squamous cell carcinoma: a systematic review and meta-analysis. $\mathrm{Br} J$ Dermatol 2011, 164:291-307.

6. UweWollina: Cetuximab in non-melanoma skincancer. Expert Opin Biol Ther 2012, 12(7):949-956.

7. Ho T, Byrne PJ: Evaluation and initial management of the patient with facial skin cancer. Facial Plast Surg Clin North Am 2009, 17:301-307.

8. Jambusaria-Pahlajani A, Miller CJ, Quon H, Smith N, Klein RQ, Schmults CD: Surgical monotherapy versus surgery plus adjuvant radiotherapy in high-risk cutaneous squamous cell carcinoma: a systematic review of outcomes. Dermatol Surg 2009, 35:574-585.

9. Sadek H, Azli N, Wendling JL, Cvitkovic E, Rahal M, Mamelle G, Guillaume JC, Armand JP, Avril MF: Treatment of advanced squamous cell carcinoma of the skin with cisplatin, 5-fluorouracil, and bleomycin. Cancer 1990, 66(8):1692-1696.

10. Fogarty GB, Conus NM, Chu J, McArthur G: Characterization of the expression and activation of the epidermal growth factor receptor in squamous cell carcinoma of the skin. Br J Dermatol 2007, 156:92-98.

11. Schlauder SM, Calder KB, Moody P, Morgan MB: HER2 and EGFR expression in cutaneous spindle squamous cell carcinoma. Am J Dermatopathol 2007 29:559-563.

12. Maubec E, Duvillard P, Velasco V, Crickx B, Avril MF: Immunohistochemical analysis of EGFR and HER-2 in patients with metastatic squamous cell carcinoma of the skin. Anticancer Res 2005, 25:1205-1210.

13. Maubec E, Petrow P, Scheer-Senyarich I, Duvillard P, Lacroix L, Gelly J, Certain A, Duval X, Crickx B, Buffard V, Basset-Seguin N, Saez P, Duval-Modeste AB, Adamski H, Mansard S, Grange F, Dompmartin A, Faivre S, Mentré F, Avril MF: Phase II study of cetuximab as first-line single-drug therapy in patients with unresectable squamous cell carcinoma of the skin. J Clin Oncol 2011, 29:3419-3426

14. Preneau S, Rio E, Brocard A, Peuvrel L, Nguyen JM, Quéreux G, Dreno B: Efficacy of cetuximab in sqamous cell carcinoma. J Dermatol Treat 2014 25:424-427.

15. Matthews BA, Rhee JS, Neuburg M, Burzynski ML, Nattinger AB: Development of the facial skin care index: a health-related outcomes index for skin cancer patients. Dermatol Surg 2006, 32(7):924-934.

16. Rowe DE, Carroll RJ, Day CL Jr: Prognostic factors for local recurrence, metastasis, and survival rates in squamous cell carcinoma of the skin, ear, and lip. Implications for treatment modality selection. J Am Acad Dermatol 1992, 26:976-990.

17. Rowe DE, Carroll RJ, Day CL Jr: Long-term recurrence rates in previously untreated (primary) basal cell carcinoma: implications for patient follow-up. J Dermatol Surg Oncol 1989, 15:315-328.

18. Hulyalkar R1, Rakkhit T, Garcia-Zuazaga J: The role of radiation therapy in the management of skin cancers. Dermato/Clin 2011, 29:287-296.
19. Mendenhall WM, Amdur RJ, Hinerman RW, Cognetta AB, Mendenhall NP: Radiotherapy for cutaneous squamous and basal cell carcinomas of the head and neck. Laryngoscope 2009, 119:1994-1999.

20. Han A, Ratner D: What is the role of adjuvant radiation therapy in the treatment of cutaneous squamous cell cancer with per neural invasion? Cancer 2007, 109:1053-1059.

21. Banci Buonamici F, De Angelis C, lotti C, Paiusco M, Olmi P, Rosi A, Tabocchini MA: Rapporto ISTISAN 08/12. In Istituto Superiore della Sanità: 2008:72. viii.

22. Herbst RS, Shin DM: Monoclonal antibodies to target epidermal growth factor receptor-positive tumors: a new paradigm for cancer therapy. Cancer 2002, 94:1593-1611.

23. Sunada H, Magun BE, Mendelsohn J, MacLeod CL: Monoclonal antibody against epidermal growth factor receptor is internalized without stimulating receptor phosphorylation. Proc Natl Acad Sci U S A 1986, 83:3825-3829

24. Saki M, Toulany M, Sihver W, Zenker M, Heldt JM, Mosch B, Pietzsch HJ, Baumann M, Steinbach J, Rodemann HP: Cellular and molecular properties of $90 \mathrm{Y}$-labeled cetuximab in combination with radiotherapy on human tumor cells in vitro. Strahlenther Onkol 2012, 188:823-832.

25. Krause M, Gurtner K, Deuse Y, Baumann M: Heterogeneity of tumour response to combined radiotherapy and EGFR inhibitors: differences between antibodies and TK inhibitors. Int J Radiat Biol 2009, 85:943-954.

26. Gurtner K, Deuse Y, Bütof R, Schaal K, Eicheler W, Oertel R, Grenman R, Thames H, Yaromina A, Baumann M, Krause M: Diverse effects of combined radiotherapy and EGFR inhibition with antibodies or TK inhibitors on local tumour control and correlation with EGFR gene expression. Radiother Oncol 2011, 99:323-330.

27. Huang SM, Harari PM: Modulation of radiation response after epidermal growth factor receptor blockade in squamous cell carcinomas: inhibition of damage repair, cell cycle kinetics, and tumor angiogenesis. Clin Cancer Res 2000, 6:2166-2174.

28. Dittmann K, Mayer C, Rodemann HP: Inhibition of radiation-induced EGFR nuclear import by C225 (Cetuximab) suppresses DNA-PK activity. Radiother Oncol 2005, 76:157-161.

29. Dittmann K, Mayer C, Rodemann HP: Nuclear EGFR as novel therapeutic target: insights into nuclear translocation and function. Strahlenther Onkol 2010, 186:1-6

30. Rhee JS, Matthews BA, Neuburg M, Logan BR, Burzynski M, Nattinger AB: Validation of a quality-of-life instrument for patients with nonmelanoma skin cancer. Arch Facial Plast Surg 2006, 8(5):314-318.

31. Rhee JS, Matthews BA, Neuburg M, Logan BR, Burzynski M, Nattinger AB: The skin cancer index: clinical responsiveness and predictors of quality of life. Laryngoscope 2007, 117(3):399-405.

32. Chren MM, Lasek RJ, Sahay AP, Sands LP: Measurement properties of Skindex-16: a brief quality-oflife measure for patients with skin diseases. J Cutan Med Surg 2001, 5(2):105-110.

\section{doi:10.1186/1471-5945-14-15}

Cite this article as: Falivene et al: Tomotherapy concomitant with cetuximab, followed by cetuximab as single-agent therapy for unresectable squamous cell carcinoma of the skin: a case report. BMC Dermatology 2014 14:15.

\section{Submit your next manuscript to BioMed Central and take full advantage of:}

- Convenient online submission

- Thorough peer review

- No space constraints or color figure charges

- Immediate publication on acceptance

- Inclusion in PubMed, CAS, Scopus and Google Scholar

- Research which is freely available for redistribution 